\title{
Hybridity in Female Indian Diasporant: A Study of the Mistress of Spices
}

\author{
Ali Salami ${ }^{*}$, Farnoosh Pirayesh ${ }^{2}$ \\ ${ }^{1}$ University of Tehran, Faculty of Foreign Languages and Literatures \\ ${ }^{2}$ University of Tehran, Alborz Campus
}

*Corresponding Author: Ali Salami, University of Tehran, Faculty of Foreign Languages and Literatures, Iran

\begin{abstract}
The present paper investigates the redeeming force of hybridity in female Indian diasporant in Chitra Banerjee Divkaruni's The Mistress of Spices. Tilo, the heroine of this novel, leaves her homeland in the hope of integrity, autonomy and a better life. She craves for America like a baby that craves for the mirror image. However, as the subject of the Lacanian Mirror stage undergoes shatter in the identity, she undergoes the same fracture in that of hers. Therefore, in the host land she undergoes unhomliness. In other words, she becomes an outsider not only to her host country but also to her home country, and as a result she loses the world in which she has forged her very identity. Yet in order to come in terms with the confusion of identities, to resolve the problem of being drawn toward both countries, she balances her dual-identities. Therefore, she resolves her fractured identity, negotiates borders, emerges as a successful woman and alters her roles and her identity and better to say assumes a new identity. In other words, she experiences the so-called hybridity and in-betweenness. A study in the light of Homi Bhabha's insights seeks to demonstrate that being positioned in the Third space and experiencing unfixed identities pave the way for her liberation.
\end{abstract}

Keywords: identity; hybrid; third space; Lacan; Bhabha

\section{INTRODUCTION}

The term hybridity came into being in post-colonial studies to respond to "static and essentialist" concepts of race and nation developed by colonial discourses (Childs and Fowler 112). The word was previously used in colonial discourses for mixed race progeny and therefore it formed a major term in discourses of colonial racism (112). Homi Bhabha, who introduces the word within colonial and postcolonial contexts, has theorized and enunciated the term vastly (112). In fact, he is named by some as the "father of hybrid theory," who believes in the mutual dependence of colonizers and colonized in forming a "shared culture" (Yazdiha 31).

He maintains that all cultural statements and systems are shaped in a space that he terms the 'the Third space of enunciation' (37). For Bhabha, it is in this conflicting and ambivalent space that cultural identity comes into being, which highlights the fact that cultures are not pure (108). For him, once this ambivalent space of cultural identity is recognized, one can vanquish the "exoticism of cultural diversity" and find an "empowering hybridity" within which cultural distinction may function:

It is significant that the productive capacities of this Third Space have a colonial or postcolonial provenance. For a willingness to descend into that alien territory . . . may open the way to conceptualizing an international culture, based not on the exoticism of multiculturalism or the diversity of cultures, but on the inscription and articulation of culture's hybridity.(38)

The meaning and weight of culture are carried within the 'in-between' space (Ashcroft et al. 109).

The present paper highlights the experience of a diasporic woman, Tilo, who is torn between two countries of the host and home, who accordingly undergoes the loss of her already forged identity and through a mirror, the reminder of a Lacanian mirror stage, views how shattered her identity has become. Moving through this mirror stage, she negotiates her identity and carves out a new one, a hybrid one. Therefore, to depict all these, the present paper is divided into three parts: Tilo (between home and host), Tilo (the mirror stage), and Tilo (the hybrid). 


\section{TILO (BETWEEN HOME AND HOST)}

Homi Bhabha believes that the question of identity "always poised uncertainly, tenebrously, between shadow and substance" and that the image of self and subsequent self-consciousness is "at once refracted and transparent" (49). Espín maintains that "identities expected and permitted in the home culture are frequently no longer expected or permitted in the host society" (ctd. in Lamor 51). She, furthermore, holds that "[a]s migrants cross borders they also cross emotional and behavioral boundaries.... One's life and roles change. With them, identities change as well" (8). Leaving their home countries, the diasporants, as Bose suggests, "disrupt [a] tidy view of nation, narration, and belonging" (ctd. in Lamor 12). Specifically, diasporic women often find themselves as a member of "multiple cultures" concurrently (13). That is to say, they are both members of their ethnic culture and that of the host country (13). Therefore, they experience confusion of identity (15). According to Sahoo, "Immigrants often face the problem of identity at the initial stage of their settlement in the host society" (ctd. in Lamor 16). In other words, the postcolonial woman is in a quest for identity while she encompasses both the self and other concomitantly (16). Then, once an individual moves from a country to another, their "ideas about homeland, nationality, role, responsibility, desire, obligation, expectation, and perception are challenged" (26). The immigrant is, on the one hand, an outsider to their home country, and on the other, an outsider to the host country (26).

The Indian women who live abroad are torn between two opposing values: old and new ones, and it is what Chitra Banerjee Divakaruni in this novel concentrates on (Saifee and Sharma 241). She depicts women who find themselves in "an in-between state" who struggle to forge identities for themselves (241). Her heroine, Tilo, is the typical immigrant who represents the type of struggles that the majority of immigrants undergo, i.e. their attempt to balance both their "heritage and life" in the new host country (Lamor 44). After settling in America in a small shop, Tilo is in an "interstitial space," so, on the one hand, she cannot forget her past while, on the other, she tends to go forward in life (Cooppan 24). She lives 'in-between' because the island is no more her home, and America is yet unfamiliar to be her home (24). While she settles in California, she cannot forget her time with the First Mother and the memories of the island and warnings keep haunting her day and night and create clashes in her present life (24). As her relationship with Raven goes forward, she finds the presence of the past inevitable, because the First Mother's possible rebukes occupy her consciousness (25), "The spice's silence is like a stone in my heart, like ash on my tongue. Through it I can hear back to long ago, the Old One laughing bitter as bile. I know what she would say were she here" (Divakaruni 62). And beyond the limits of time and space, Tilo communicates with the First Mother (Cooppan 25). Therefore, her predicament is an "allegory of the immigrant who experiences the dual pull of the charm of the past and the call of the present" (Upadhyay and Shah 2).

Bhabha holds that "the negating activity is, indeed, the intervention of the 'beyond' that establishes a boundary: a bridge, where 'presencing' begins because it captures something of the estranging sense of the relocation of the home and the world - the unhomeliness - that is the condition of extra-territorial and cross-cultural initiations" (9). Bhabha tersely puts that "to be unhomed is not to be homeless, nor can 'unhomely' be easily accommodated in that familiar division of social life into private and public spheres" (9). The sense of 'unhomeliness' emerges at the "rite of extra-territorial and cross-cultural initiation" (9). When displacement occurs, the boundary between home and world is blurred, the private and the public become entangled, and they create a divided and disorienting vision (9). When for the first time Tilo leaves the spice shop, she longs intensely for a place called home (Cooppan 2526): "I run my hand over the door, which looks so alien in outdoor light, and I am struck by the sudden vertigo of homelessness" (Divakaruni 62). Traditionally speaking, Tilo does not possess a home and America is only one "point in between her geographical migrations" (Cooppan 26). Although Tilo has left the Island, she is aware that she will someday go back to it, to that place that is still 'in between' worlds, so far "remains the only location in which she feels the comfort of belongingness" (26). Hence, Tilo's emotions depict "an extreme version of the diasporic experience of space" where "continents are separated not by miles but by universes, where home does not exist except in the space of idealizing memory" (26). It is manifest that "lack of cohesion in the lives of immigrants" leads to the creation of a place in which an immigrant no more feels at home anywhere, and afterwards, they lose their "sense of past, present, and future" at once (Lamor 26). And the loss of space to which one belongs is the same as the loss of the world where one has carved out their identity (26). Therefore, one is struck with "loss and lack of belonging" (26). The immigrant's "sense of self 
and personal identity becomes fractured" (28). Guha mentions that it is significant to "continue a little longer with our concern for the impasse in which, literally, [the migrant] finds himself: stranded between a world left behind and another" (ctd. in Lamor 29).

In effect, immigrants may idealize their native culture and resist acculturation and they may deem that their values and customs can stabilize personal identity and also sticking to their norms can protect them from the so-called pain of fractured identity (51). Considering her behavior in the shop, Tilo is the typical example of the "traditional submissive Indian woman"and she is perceived accordingly by her customers (Cooppan 33). It is noteworthy that Indian culture secures a special role for a woman in a family. A woman in the family is know-it-all, i.e. she does know who needs what; the same is true in the novel, that is to say Tilo already knows what the customers need, which gives the impression that the shop is a home, an Indian home (Upadhyay and Shah 3). Amusingly, the rules that she must abide by as a mistress of spices accord with those that an Indian American woman must obey (Lamor 74). That is to say, she must sacrifice her needs and desires to satisfy those of others (74). Tilo remembers that the First Mother told her that 'You are not important. No Mistress is. What is important is the store. And the spices' (Divakaruni 11) and "a Mistress must carve her own wanting out of her chest, must fill the hollow left behind with the needs of those she serves" (37). As a result, Tilo represents how an Indian woman must be: selfless (Upadhyay and Shah 5).

Clearly, the First Mother represents the" traditionalist notion of the South Asian woman in the domestic sphere" (Cooppan 22). As a result, tradition and rules in the form of the first Mother keep plaguing and threatening her throughout the novel. For instance, Tilo remembers the Old Mother's saying that if a Mistress grows "rebellious and self-indulgent, fails her duty" she "must be recalled" and once she is warned, "she has three days only to settle her affairs. Then Shampati's fire blazes for her once more." But this time while "entering she feels it fully, scorch and sear, the razors of flame cutting her flesh to strips. Screaming, she smells her bones shatter, skin bubble and burst" and when she breaks many rules she gets the warning that 'Shampati's fire calling me back' (Divakaruni 32-102). Or when Harun kisses her hand she remembers the First Mother "warned me against" it (20). The old One, furthermore, has told her that "the Mistresses must never use the spices for their own ends" (38). The first Mother later haunts her in the shop "Tilo daughter you should not have" after Tilo visits Geeta and leaves the shop (66).

How one perceives their identity and how they are perceived by others play a significant role in one's identity formation (Lamor 46). At first, Tilo perceives herself through the lenses of others "a bent woman with skin the color of old sand, behind a glass counter that hold...sweets of their childhoods. Out of their mothers' kitchens" (Divakaruni11), Tilo describes herself as having an "old woman voice" and an "old woman body" (53) covered with "creases and gnarls," and with wrinkles like "old snake skin" (11). She respects the elders who come to the store, referring to older men as "dada," a term of high respect. She is not "seductive but rather matronly," moreover, she does not express her opinions and proffers advice only when she is asked (Kaur 80). Yet as the story goes on she begins to assimilate to American culture, and she comes to perceive herself (Cooppan 20). She finds out that she is made up of various identities ascribed to her, and consequently she recognizes her "multiple consciousness" (21). Therefore, she is pushed into the confusion of American life and the novelty of a culture to which she must become accustomed (21). Tilo's life is replete with contradictions which result in her fractured identity (Lamor 74). She is "torn in terms of her own self-identity" (74). And in order to satisfy both her desires and those of others, she must acquire how "to maneuver the fracturing she experiences throughout the novel" (74). She must both follow the guidelines and successfully negotiate the "fragmentation of her self" for example while she must stay in the shop, she leaves it at her own peril (74).

On her quest for hybrid identity, Tilo gradually breaks the rules as she leaves the store to help others, which is forbidden to the mistresses. Of course, owing to breaking the mistress rules, she thinks she will face the "punishment," and as a result, "Shampati's fire calling me [her] back" (102). Yet, she simultaneously resists, and she is unwilling to accept her fate "Why am I wrenched at the thought that it will all be here, all except me "Tilo wonders as she gets ready to go back to her home away from the U.S. (105). Thus, Tilo is willing to rebel and break free from the shackles (Upadhyay and Shah 6). She grapples with her own self and becomes involved in "an emotional relationship with a native American man" called Raven (6). Although change is not an easy task for her and she feels guilty, she is intrepid enough to face the outcome to go against the rules of the mistresses and to make decisions 
about her life (7). Therefore, she suffers from the "conflict within" (7). In fact, in order to negotiate her fragmented identity, she must undergo more fracturization which is achieved though her forays to going out (Lamor 75). When for the first time she "step[s] onto the forbidden concrete floor of America, leaving behind the store as she is never supposed to do" in order to see Harun's taxi, she thinks she hears the store's displeasure: "Behind me a hiss like a shocked, indrawn breath" (Divakaruni 21).

The second time venture into going out of the shop is easier and she is "getting better at it, bending the spices' will to mine. This time the heartsickness is less. And the guilt which I will not look in the eye " (62). For her as she says "The first step wrenches, bone and blood, rips out our breath. The second too racks but already it is not so strong. With the third the hurting passes over our bodies like a raincloud. Soon it will not give us pause, or pain" (62). Once she wears American clothes and walks out of the store, she undergoes a remarkable change between "states of mind" and has a consciousness that she thinks is that of an American while simultaneously "it is a foreign and 'other' consciousness for her" (Cooppan 31). She says that

... I pull on my no-nonsense pants and polyester top, button my nondescript brown coat all the way to my calves. I lace my sturdy brown shoes, heft my brown umbrella in readiness. This new-clothed self, I and not-I, is woven of strands of brownness with only her young eyes and her bleached jute-hair for surprise. She tries a hesitant smile which resettles her wrinkles...Outside at a bus stop crowded with other strands of brown and white and black she will get into line, will marvel that no one even raises their eyes, suspicious at her moving through the air of America...She will finger in pleased wonder the collar of her coat, which is better even than a cloak of disappearing. And when the bus comes, she will surge at it with the others, her blending so successful that you standing across the street will no longer know who is who. (Divakaruni 63)

The first time that she reveals the duality in her consciousness is when she says "I and not-I" (Cooppan 31). Interestingly, for Tilo her 'in-betweenness' is a "positive sensation," which gives her "pleased wonder" (32). The "shift in her consciousness" is, furthermore, implied by the alteration in pronouns-the narrative 'I' changes to 'she' while she describes herself through the eye of an American (32). It is as if Tilo were a different individual, however, she knows that this "new woman is still 'herself"' (32). Tilo espouses the idea that "she can blend in with America and be a part of it" (32). When she is waiting at the bus stop, she takes relish in the fact that she is no more different and she can not only stand among Americans but also becomes as an American, so that no one could tell "who is who" (32).

It must be added that her transportation to America occurs through 'Shampati's Fire," a giant bonfire into which she walks and vanishes (23). Symbolically the fire destroys the present physical form and reduces her to ashes that will be moved to America (23). In other words, the fire is a metaphor for recreating" the self and presenting identity as erratic rather than permanent" and it foreshadows the process of Tilo's identity formation" (23-24). Just as the Shapati's fire refers to phoenix and its rising from ashes, Tilo's journey to America is a kind of "rebirth and a "literal recreation of the self" (24).

\section{Tilo (The Mirror Stage)}

Bhabha talks about the notion of self-reflection in The Location of Culture. He concentrates on one common belief of identity discussion, "the philosophical tradition of identity as the process of selfreflection in the mirror of (human) nature" and discusses that "[I]n the postcolonial text the problem of identity returns as a persistent questioning of the frame, the space of representation... is confronted with its difference, its Other" (46). Bhabha, furthermore, stresses that "What is so graphically enacted in the moment of colonial identification is the splitting of the subject" (46). In this novel, Divakaruni makes use of the mirror to refer to the fractured identity engendered by the immigrant experience (Lamor 48).

Lacan's concept of the mirror-stage is manifest in many scenes and is explored many times. Tilo is not allowed to look at her reflection in a mirror based on the mistress rules "for mirrors are forbidden to Mistresses" (Divakaruni 11) and she eschews seeing her reflection on the window earlier in the novel "In the grey window glass which is the store's only mirror, the shadow of my face wavers for a moment" yet she "shut my[her] eyes, move away" because "Once a Mistress has taken on her magic 
Mistress-body, she is never to look on her reflection again" (33). This banning is a "metaphor" for her incapability of perceiving herself (Cooppan 27). However, as she keeps on growing and changing, her desire to look at the mirror also increases (Lamor 46). She even buys one while she does not know "what I will need it for I cannot yet tell" (Divakaruni 63), and there is a constant struggle not to look at it; she is even once elated at the idea of seeing herself (Lamor 46) and once when she is nearly tempted to look at it, she says "But not today. It is not time" (Divakaruni 67). It is obvious that the mirror stage is the moment of recognizing self, and Tilo's yearnings to look at it play a key role in developing her character (Lamor 46). It must be noted that she expects too highly of the mirror "Mirror, forbidden glass that I hope will tell me the secret of myself" (Divakaruni 67). Not only does Tilo wish to recognize herself in the mirror, but also she pines for the Lacanian identification through which she can "identify herself as independent, autonomous, and self-realized" (Lamor 47).

At the moment that she puts the prohibition of mirrors for mistresses into question, she achieves "selfperception"(Cooppan 36), she says "Here is a question I never thought to ask on the island: First Mother, why is it not allowed, what can be wrong with seeing yourself?" (Divakaruni 67). Homi Bhabha asserts that "the very place of identification, caught in the tension of demand and desire, is a space of splitting" (44). Ironically, looking into the mirror, at first, like the Lacanian subject, she is

dazzled by the face looking back at me, young and ageless at once, the fantasy of fantasies come to life, spice power at its fullest. Forehead flawless like a new opened shaplaleaf, nose tipped like the tilflower. Mouth curved as the bow of Madan, god of love, lips colour of - there are no other words for this - crushed red chillies. For kisses that will burn and consume. (Divakaruni 120)

But simultaneously, the Lacanian Ideal-I is shattered, she does not find the truth about identity, in its stead she sees that

It is a face that gives away nothing, a goddess-face free of mortal blemish, distant as an Ajanta painting. Only the eyes are human, frail. In them I see Nayan Tara, I see Bhagyavati, I see the

Tilo who was. Wide elated eyes, but also telling me something I did not expect. (120)

She, therefore, finds out that she has lost all the human qualities in her quest for a unified identity (Cooppan 37). She fathoms out that instead of a unified identity she has one of "multiplicity and ambiguity," that is to say, she is made up of several and conflicting "perceptions of the self" (37).

\section{TILO(THE HYBRID)}

Hybridity occurs at the "border of diaspora," in which the diasporant encounters and communicates with the 'host society', or with other "diasporic cultures and identities," and where "new cultural forms and identities" come into view (Collins and Solomos 497). Hybridity, in other words, is considered as the "culture of borderline, of the in-between, of what AvtarBrah calls 'diasporic space' (497). For Bhabha, in addition, hybridity is the third space and "how newness enters the world" (212). Homi Bhabha's hybridity demonstrates the space in between cultures, at the border of "belonging and alienation" (Sandra 148). It is called upon to articulate "marginal identities that foster plurality and replace exclusive dichotomies" (148).Hybridity functions as a regular movement between spaces and passes "through and between identity itself" and this latitude to move between identities does defy the allegations of "essentialized racial identity" (Yazdiha 33).Identity, a site in which the notions of diaspora and hybridity connect, is constructed in "interaction and contestation with both old and new homelands and forged in the 'turbulence of migration"' (Collins and Solomos 497). Subjects, therefore, are shaped 'in-between' and such an in-between space bridges the home and the world (Bhabha 2-13). Homi Bhabha believes that the significance of hybridity is not being able to trace two original moments from which the third spaces appears, rather hybridityis the 'third space' which causes other positions to come out (Mehta 146). It is so owing to the fact that Bhabha prioritises neither the motherland, nor the host country instead he highlights a middle ground that he calls the "Third space." The third space is the space of hybridity, where "cultural meanings and identities" bear the marks of other meanings and identities (Ashcroft et al. 53-54).

Owing to being positioned in this 'in-between' space, the Indian woman living abroad forms an "altered consciousness" so that she can connect to her native culture while concurrently she adapts to her present American setting (Cooppan 2). Thus, Tilo learns that she must acknowledge the 
multiplicity of her identity and espouse the conflicting consciousnesses (37-38). She stands inbetween "categorical constructions of racial and sexual identities" (4). She does not struggle to be one person or another, instead she is neither, and she is not defined by normal terms of describing one's identity (4). Owing to the undetermined nature of her "interstitial environment," the manner in which she sees herself alters and as a result her "self-perception" changes (5). Divakaruni's heroine can live in a world where the person exists "not as a unified One, but rather as many, bound by no borders and infinite in the possibilities of creating consciousness and inventing identities" (5).

As the novel reaches the end, Tilo lives in "the world in which her Indian-ness and her American-ness are both challenged to the extent that she is left unable to reconcile the two - within herself and within her relationships and community" (Lamor 79). And as she has reached the utmost point of her fractured identity, i.e. she is no longer at the mercy of the mistress rules, she finds herself as one complete woman and she is whole and she is no more wavering between two as she says "This is not a body in youth's first rose glow, but not one in age's last unflowering either" (Divakaruni 130). Even though the physical world around is in utter chaos, she feels "strangely weightless, my whole body a smile, like an obstacle runner who never thought she would make it and now has just sailed over the last hurdle" (132). As she finds a voice as well as strength, she rejects Raven's idea of going away to find a paradise, she says: "No. My voice sounds ungracious, adamant. I wish I could acquiesce graciously, as women - Indian and not Indian - are asked so often to do. Kiss away conflict. But I know I am right not to" (132). Tilo prefers to come back to the earthquake struck city because she realizes that the "fracturization that she has experienced - the rending apart of herself as an immigrant, as a woman, as an Indian- American person - is a part of who she is" (Lamor 81). Moreover, to resolve that condition successfully, she must acknowledge it and learn "how to navigate within it" (81). Therefore, she says to Raven that "I cannot go with you" while "The words are crooked bones I must pull, bleeding, from my throat" (Divakaruni 134). Still, although she is physically in pain, she articulates to Raven that:

There is no earthly paradise. Except what we can make back there, in the soot in the rubble in the crisped-away flesh. In the guns and needles, the white drug-dust, the young men and women lying down to dreams of wealth and power and waking in cells. Yes, in the hate in the fear. (134)

Gita Rajan aptly says that "the sum of [Tilo's] immigrant, diasporic, racialized, and gendered experiences in America make it possible for her to negotiate the outcome of events" (Lamor 81). At last, she has broken away from all "expectations, rules, desires of others and finally in her moment of resolution found the ability to voice her own needs, and a willingness to build life within the fracturization" (82). She is ready to construct her new sense of self, to put it in Raussert's terms: "Returning to the earthquake area, she demonstrates that she has integrated motherly instructions for social responsibility into her own dream of self-fulfillment" (ctd. in Lamor 82). Furthermore, VegaGonzález holds that "Tilo does not want to renounce her human right to love and be loved," and "At the end of the novel, Tilo's dilemma is resolved happily" (ctd. in Lamor 82). At the end as she pines for a new name, her becoming whole is complete Vega-González highlights the significance of this final act, "an act which significantly represents the complexity of her identity" (ctd. in Lamor 82).

She needs a name that "spans my land and yours" (Divakaruni 135). When Raven suggests Maya, she remembers that "in the old language it can mean many things" like "the power that keeps this imperfect world going day after day" and says "I need a name like that, I who now have only myself to hold me up" (135). Christina Bacchilega asserts that "Maya is a name that 'dissolves boundaries"' (ctd. in Lamor 83). Eventually, Maya - who was Nayan Tara and Tilottama and a Mistress of Spices reaches a point of "resolution as a self-realized woman" (83). The name Maya that she opts for is in line with her multiple identities because it "can mean many things. Illusion, spell, enchantment, the power that keeps this imperfect world going day after day" (Divakaruni 135). Additionally, Maya is "an ancient Sanskrit name," and it represents a "cultural past and Tilo's present power" (Cooppan 38). As a result, it implies that she lives in-between spaces (38). In this naming, then, she depicts what she is made up of: "multiple consciousnesses" which allows her to live"not as South Asian or American only, but rather as everything in between, living a life that spans the endless boundaries of space and time and in which identity is filled with the promise of endless possibility and eternal evolution" (38- 
39). Vega-González observes that in the final chapter of Tilo's negotiation of fracture she reaches cohesion: "Like many other immigrants, Tilo's identity is composed by an Indian part and an American part; it is, in other words, a 'transnational hybridized identity'" (ctd. in Lamor 83). That is to say Tilo's predicament of "cross-cultural identity formation" is resolved as she gathers the contradictions (Cooppan 21). Simply put, at the end of the novel, devoid of her magical powers, she turns into Maya and she finds her new home through "an act of cultural translation" (Upadhyay and Shah 7).

In this novel, Divakaruni offers a " reaffirming message of hope and strength within specifically female negotiation of fracturization" (Saifee and Sharma 242). She, furthermore, proffers "empowerment to women of diaspora on various levels, including solidarity with other women and acknowledgment of the supportive, healing role women often play (individually and communally) (242). She, most importantly, provides a platform from which she highlights the power of women (242). The 'third space' of hybridity and the margins of the diasporic "have been offered to the sacred altar of resistance as new sites of hope"(Mitchell 257). An Immigrant needs to find balance between the parts of themselves, in this regard Lisa Lau holds that"from the contemporary writings of the diasporic South Asian women, it appears that South Asian women of diaspora feel the tug of loyalties and confusion of identities until they learn to balance dual-identities or double consciousness, and combine those into a certain equilibrium" (ctd. in Lamor 69). She is obviously successful at getting over her fractured identity and developing a new one and in this way Divakaruni depicts a "reaffirming message of hope and strength within specifically female negotiation of fracturization" (89). Tilo endeavours to define herself as both South Asian and American and simultaneously she "develops multiple levels of consioucsness that manifest themselves in both, her experiences and her subsequent relationships with her racial and sexual identities" (Kaur 79). She embraces the multiplicities within her identity and becomes a "fully realized and recognized person" (54). Her violating the mistress rules and expressing herself as an individual with a power to decide, she reaches the acme of her identity formation, as if she were 'born' into a new identity (47). Tilo recognizes, interprets and resolves the fractures and finally finds both "strength and empowerment" (25). Therefore, Tilo, the South Indian woman, resolves her identity fracturization, becomes independent, autonomous, supports men and becomes successful as a woman, an Indian, an American, an individual, and a member of her new community (Saifee and Sharma 242).

\section{CONCLUSION}

This novel highlights the struggles and challenges that an immigrant, Tilo, undergoes in order to adapt to her life in America and manifests how she undergoes loss of her already forged identity due to her immigration to America. On her quest for hybridity, she feels unhomely in the host country, is torn between the host and the home countries but, at last she manages to resolve her fractured identity caused by immigration and she negotiates the differences and becomes a hybrid.

\section{REFERENCES}

[1] Ashcroft, Bill, Gareth Griffiths, and Helen Tiffin. Post-colonial Studies: The Key Concepts. London: Routledge, 2007. Print.

[2] Bhabha, Homi K. The Location of Culture. London: Routledge, 1994. Print.

[3] Mehta, Brinda. "Notions of Identity, Diaspora, and Gender in Caribbean Women's Writing." (2009). Print.

[4] Childs, Peter, and Roger Fowler. The Routledge Dictionary of Literary Terms. Oxen:

[5] Routledge, 2006. Print.

[6] Collins, Patricia, and John Solomos. The SAGE Handbook of Race and Ethnic Studies. Los Angeles: SAGE, 2010. PDF.

[7] COOPPAN, SUMANA. "'CREATING CONSCIOUSNESS AND INVENTING IDENTITY 'An Examination of Self-Perception, Multiple Consciousness and the Process of South Asian Diasporic Identity Formation in Selected Works by Bharati Mulherjee and Chitra Banerjee Divaltaruni." Thesis. WILLIAMS COLLEGE, 2004. Web. 22 July 2015.

[8] Divakaruni, ChitraBannerjee. The Mistress of Spices. Doubleday: Black Swan, 1997. PDF.

[9] Kaur, Monbinder. "Blurring Borders/Blurring Bodies: Diaspora and Womanhood." Exploring Gender in the Literature of the Indian Diaspora. Ed. Sandhya Rao Mehta. Cambridge Scholars, 2015. 
[10] Lamor, Lisa. "Fractured Identity - The Jagged Path of Diaspora in Chitra Banerjee Divakaruni'sThe Mistress of Spices." Thesis. Minnesota State University, 2011. Web. 22 July 2015.

[11] Mitchel, Katharyne. "Different Diasporas and the Hype of Hybridity." Environment and Planning D: Society and Space 15.5 (1997): 257-77. Web. 22 June 2015.

[12] Saifee, Rukhsana, and Mukta Sharma. "ChitraBannerjeeDivakaruni's Literature on the Dilemma of Women Living in Alien Culture."The Criterion: An International Journal in English 4.VI (2013): 241-43. Web.

[13] Upadhyay, Ami, and Pratima Shah. "Feminist Sensibility in Diaspora Writer ChitraDivakaruni'sThe Mistress of Spices."IJRAR- International Journal of Research and Analytical Reviews 2.2 (2015): 1-9. Web. 22 June 2015.

[14] Yazdiha, Haj. "Conceptualizing Hybridity: Deconstructing Boundaries through the Hybrid."Formations 1.1 (2010): 31-38. Web.

\section{AUTHOR's BIOGRAPHY}

Ali Salami, PhD. is an Assistant Professor of English literature at the University of Tehran. An internationally published author, Salami has written extensively on gender and discourse, Shakespeare and postcolonial literature. He can be reached at salami.a@hotmail.com.

Farnoosh Pirayesh is a PhD student majoring in English Literature at Tehran University, Alborz Campus. She has been conducting some in-depth research on South Asian diaspora recently. Furthermore, her research interests cover a range of topics from psychoanalysis to post-colonialism.

Citation: Ali Salami, Farnoosh Pirayesh. Hybridity in Female Indian Diasporant: A Study of the Mistress of Spices. International Journal on Studies in English Language and Literature (IJSELL), vol 6, no. 3, 2018 , pp. 11-18 doi:http://dx.doi.org/10.20431/2347-3134.0603003.

Copyright: (C) 2018 Authors. This is an open-access article distributed under the terms of the Creative Commons Attribution License, which permits unrestricted use, distribution, and reproduction in any medium, provided the original author and source are credited. 